\title{
Article
}

\section{Mechanism of enhancement of intumescent fire retardancy by metal acetates in polypropylene}

Zhang, Yan, Li, Xiaonan, Fang, Zhengping, Hull, T Richard, Kelarakis, Antonios and Stec, Anna A

Available at http://clok.uclan.ac.uk/16796/

Zhang, Yan, Li, Xiaonan, Fang, Zhengping, Hull, T Richard ORCID: 0000-00027970-4208, Kelarakis, Antonios ORCID: 0000-0002-8112-5176 and Stec, Anna A ORCID: 0000-0002-6861-0468 (2017) Mechanism of enhancement of intumescent fire retardancy by metal acetates in polypropylene. Polymer degredation and Stability, 136 . pp. 139-145. ISSN 0141-3910

It is advisable to refer to the publisher's version if you intend to cite from the work. http://dx.doi.org/10.1016/j.polymdegradstab.2016.12.018

For more information about UCLan's research in this area go to http://www.uclan.ac.uk/researchgroups/ and search for <name of research Group>.

For information about Research generally at UCLan please go to http://www.uclan.ac.uk/research/

All outputs in CLoK are protected by Intellectual Property Rights law, including Copyright law. Copyright, IPR and Moral Rights for the works on this site are retained by the individual authors and/or other copyright owners. Terms and conditions for use of this material are defined in the policies page.

\section{CLoK}

Central Lancashire online Knowledge www.clok.uclan.ac.uk

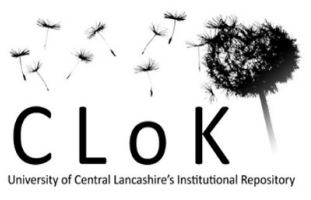




\section{Accepted Manuscript}

Mechanism of enhancement of intumescent fire retardancy by metal acetates in polypropylene

Yan Zhang, Xiaonan Li, Zhengping Fang, T. Richard Hull, Antonios Kelarakis, Anna A. Stec

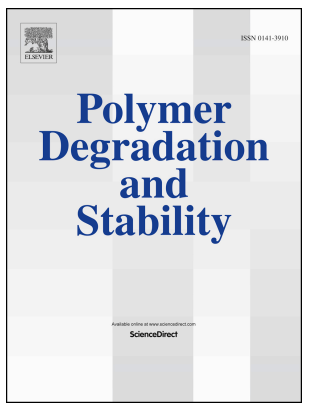

PII: S0141-3910(16)30397-4

DOI: 10.1016/j.polymdegradstab.2016.12.018

Reference: $\quad$ PDST 8139

To appear in: Polymer Degradation and Stability

Received Date: 19 October 2016

Revised Date: 20 December 2016

Accepted Date: 31 December 2016

Please cite this article as: Zhang Y, Li X, Fang Z, Hull TR, Kelarakis A, Stec AA, Mechanism of enhancement of intumescent fire retardancy by metal acetates in polypropylene, Polymer Degradation and Stability (2017), doi: 10.1016/j.polymdegradstab.2016.12.018.

This is a PDF file of an unedited manuscript that has been accepted for publication. As a service to our customers we are providing this early version of the manuscript. The manuscript will undergo copyediting, typesetting, and review of the resulting proof before it is published in its final form. Please note that during the production process errors may be discovered which could affect the content, and all legal disclaimers that apply to the journal pertain. 


\title{
Mechanism of Enhancement of Intumescent Fire
}

\section{Retardancy by Metal Acetates in Polypropylene}

\author{
Yan Zhang ${ }^{1}$, Xiaonan $\mathrm{Li}^{1}$, Zhengping Fang ${ }^{1,2 *}$, T Richard Hull ${ }^{3}$, Antonios Kelarakis ${ }^{3}$,
} Anna A. Stec $^{3}$

1 Laboratory of Polymer Materials and Engineering, Ningbo Institute of Technology, Zhejiang

University, Ningbo 315100, China

2 MOE Key Laboratory of Macromolecular Synthesis and Functionalization, Department of

Polymer Science and Engineering, Zhejiang University, Hangzhou 310027, China

3 Centre for Fire and Hazards Science, University of Central Lancashire, Preston PRI 2HE, UK

E-mail: zpfang@zju.edu.cn

\begin{abstract}
The effects of cobalt acetate (CoAc), manganese acetate (MnAc), nickel acetate (NiAc) and zinc acetate $(\mathrm{ZnAc})$ as fire retardant additive in intumescent polypropylene (PP) formulations containing PP/ammonium polyphosphate (APP)/pentaerythritol (PER) are reported. The limiting oxygen index (LOI) and vertical burning (UL94) tests and cone calorimetry were used to quantify the enhancement. Environmental chamber rheometry, thermal gravimetric analysis and the morphology of the residual char were used to investigate the mechanism of enhancement. The incorporation of small quantities of metal acetates had a significant influence on the fire behaviour. As an example, $0.7 \mathrm{wt} \%$ MnAc improved the UL 94 rating of PP/APP+PER (mass ratio 100/25, with APP/PER=3/1) sample from V-2 to V-0, while $1 \mathrm{wt} \% \mathrm{MnAc}$ reduced the peak heat release rate and the total heat release by $18 \%$ and $12 \%$ in the cone calorimeter. Rheological data, cone calorimetry, and photographs of the residual char showed how the fire retardancy of the systems were affected by the melt viscosity, which depended on the loading of metal acetate. During thermal decomposition, the metal acetates promote the crosslinking of the polymer and the fire retardant, reinforcing the protective intumescent layer. While, the effect is most potent at the optimal metal loadings. At higher MnAc loadings, the benefit of a stronger char is overwhelmed by the adverse effect of crosslinking on the transition char layer. Thus, this paper offers a new insight into the mechanism of the intumescent fire retarded PP system.
\end{abstract}

Keywords: Fire; intumescent flame retardant; polypropylene; metal acetate; rheology; mechanism 


\section{Introduction}

The fire protection of flammable polymers using an intumescent additive system is a complicated chemical processes ${ }^{[1]}$. These additive systems usually contain three main ingredients: an acid source, a carbon source, and a gas source, which decomposes, above the polymer processing temperature, to form a foamed cellular char layer, through release of gas, dehydration and crosslinking, to protect the underlying material from the action of heat or flame ${ }^{[2-4]}$. To be effective, the typical loading of the intumescent fire retardant (IFR) is around $30 \mathrm{wt} \%$, which may adversely affect the mechanical properties of polymer. Therefore, research has focused on improving the efficiency of IFR at lower loadings ${ }^{[5-7]}$.

Divalent or multivalent metallic compounds such as metal oxides ${ }^{[8,9]}$, metal chlorides $^{[7,10]}$, metal sulphates ${ }^{[9]}$, metal chelates ${ }^{[11-14]}$ and metal phosphates ${ }^{[2,15]}$ have been reported to promote the char-formation ability of the polymer/IFR systems. They can catalyse the dehydration and crosslinking between polymer chains and/or fire retardants, leading to a more continuous and stable char ${ }^{[9]}$.

The high melting points of metal oxides make it difficult to achieve good dispersion within the polymer matrix. Metal chlorides or metal sulphates may release toxic halides or sulphides on heating. In contrast, metal acetates are non-toxic or of low toxicity with lower melting points and maybe a better choice as IFR promoters. Some metal acetates are Lewis acids, which can improve the char formation. Based on the results of empirical flammability tests, limiting oxygen index (LOI), vertical burning (UL94), together with thermo gravimetric analysis (TGA), Lewin and Endo 
found that manganese and zinc acetates had synergistic effects with IFR in the fire retardancy of polypropylene (PP) ${ }^{[8]}$. They ascribed such synergy to the catalytic activity of metal compounds on the crosslinking of the polymer matrix alongside APP, which favours the formation of char, leading to better fire retardancy ${ }^{[8]}$. However, the study of metal compounds on the flame retardancy of PP by Lewin and Endo were based on the results of limiting oxygen index (LOI), vertical burning test (UL-94 rating) and thermal gravimetric analysis (TGA), which do not provide quantitative data on the burning behaviour and the functional mechanism of the metal acetate on the intumescent fire retardant PP needs further investigation.

The cone calorimeter provides detailed information on burning behaviour and can be used to predict the behaviour of materials in a real fire ${ }^{[16,17]}$. At the same time, the flow behaviour of a polymeric matrix containing IFR during heating is a key parameter needed to determine the fire retardant mechanism, since the viscosity of the molten matrix will affect the flow of fuel to the flame zone, the swelling of the intumescent layer, and the properties of the char layer, all of which will affect the heat release rate. Thus, in this paper, the effects of four metal acetates including cobalt acetate $(\mathrm{CoAc})$, manganese acetate $(\mathrm{MnAc})$, nickel acetate $(\mathrm{NiAc})$ and zinc acetate (ZnAc) in an ammonium polyphosphate (APP)/pentaerythritol (PER) based intumescent system were characterized by the LOI and UL94 tests at the beginning. This was followed by a focused study on the manganese acetate as it showed the best promotional fire retardant effects. Using rheological analysis and cone calorimetry, the mechanism of the metal acetates on the flame retardant PP was elucidated from a 
new perspective for the first time. And improved optimum concentrations of metal acetates in intumescent fire retarded PP were found different from those of Lewin and Endo ${ }^{[8]}$.

\section{Experimental}

\subsection{Materials}

PP (PPH-T03-H) was purchased from China Petroleum \& Chemical Corporation (China). Pentaerythritol (PER) and cobalt acetatetetrahydrate $\left(\mathrm{Co}\left(\mathrm{CH}_{3} \mathrm{CO}_{2}\right)_{2} \cdot 4 \mathrm{H}_{2} \mathrm{O}\right.$, CoAc)were provided by Sinopharm Chemical Reagent Co. Ltd. (Shanghai, China).Manganese(II) acetate tetrahydrate $\left(\mathrm{Mn}\left(\mathrm{CH}_{3} \mathrm{CO}_{2}\right) \cdot 4 \mathrm{H}_{2} \mathrm{O}, \quad \mathrm{MnAc}\right)$, nickel acetate tetrahydrate $\left(\mathrm{Ni}\left(\mathrm{CH}_{3} \mathrm{CO}_{2}\right) \cdot 4 \mathrm{H}_{2} \mathrm{O}, \mathrm{NiAc}\right)$ and zinc acetate dihydrate $\left(\mathrm{Zn}\left(\mathrm{OOCCH}_{3}\right)_{2} \cdot 2 \mathrm{H}_{2} \mathrm{O}, \mathrm{ZnAc}\right)$ were provided by Xiya Reagent (China), Damao Reagent (Tianjin,China) and the 2nd Chemical Reagent Company(Yixing, China), respectively. Ammonium polyphosphate (APP) was supplied by Hangzhou JLS Flame Retardants Chemical Co. Ltd. (Hangzhou, China). All chemical reagents were used without further purification.

\subsection{Preparation of flame retardant PP composites}

The compositions of the PP based composites are presented in Table 1. The ratio of APP and PER was set to $3: 1$, which generally gives the best fire retardancy performance for APP and PER combinations ${ }^{[18]}$. PP composites were compounded at $185^{\circ} \mathrm{C}$ in Thermo-Haake rheomixer with a rotor speed of $60 \mathrm{rpm}$, and the mixing time was 8 min for each sample. After compounding, the samples were then transferred to moulds suitable for each test, preheated for $5 \mathrm{~min}$ at $190^{\circ} \mathrm{C}$, and then pressed at 25 
MPa for 3 min, followed by cooling to room temperature under the same pressure for $5 \mathrm{~min}$

Table 1 Formulation of fire retardant PP composites

\begin{tabular}{lccc}
\hline Sample ID & PP(wt\%) & APP+PER(wt\%) & $\begin{array}{c}\text { Metal Acetate } \\
(\mathrm{MAc}, \mathrm{wt} \%)\end{array}$ \\
\hline PP & 100 & & \\
PP/25APP+PER & 75 & 25 & 0.3 \\
PP/25APP+PER/0.3MAc & 74.7 & 25 & 0.7 \\
PP/25APP+PER/0.7MAc & 74.3 & 25 & 1 \\
PP/25APP+PER/1MAc & 74 & 25 & 2 \\
PP/25APP+PER/2MAc & 73 & 25 & 3 \\
PP/25APP+PER/3MAc & 72 & 25 & 4 \\
PP/25APP+PER/4MAc & 71 & 25 & \\
\hline
\end{tabular}

Metal, $\mathrm{M}=\mathrm{Co}, \mathrm{Mn}, \mathrm{Ni}, \mathrm{Zn}$

\subsection{Characterisation}

Limiting oxygen index (LOI) values were determined using an HC-2 Oxygen Index instrument (Jiangning Analytical Instrument Company, China) on test strips with the dimensions of $120 \times 6 \times 3 \mathrm{~mm}^{3}$ according to ASTM D2863. The vertical burning test was conducted in a CZF-Ш horizontal and vertical burning tester (Jiangning Analysis Instrument Company, China) according to ASTM D3801-06 with the dimension of the specimens of $127 \times 12.7 \times 3 \mathrm{~mm}^{3}$. The rheological properties of PP and its fire retardant compounds were determined on a controlled strain rate parallel plate rheometer (AR2000, TA instruments, USA) under nitrogen, using $25 \mathrm{~mm}$ diameter circular samples and plates, with a plate gap of $6 \mathrm{~mm}$. The temperature scanning experiments were conducted over the temperature range from 220 to $550^{\circ} \mathrm{C}$, running with a strain of $1 \%$ and a fixed frequency of $0.1 \mathrm{rad} \cdot \mathrm{s}^{-1}$. Thermal gravimetric analysis (TGA) was performed on TGA $209 \mathrm{~F} 1$ (Netzsch, Germany) at a heating rate of $20{ }^{\circ} \mathrm{C}$ 
$\min ^{-1}$ in $\mathrm{N}_{2}$ from 50 to $700{ }^{\circ} \mathrm{C}$. The combustion parameters were measured using a cone calorimeter (Govmark, USA) according to ISO 5660 at a heat flux of $50 \mathrm{~kW} \cdot \mathrm{m}^{-2}$. The dimensions of all samples for the cone calorimetric measurements are $100 \times 100$ $\times 3 \mathrm{~mm}^{3}$.

\section{Results and discussion}

\subsubsection{Limiting Oxygen Index tests}

The results of the limiting oxygen index test (LOI) are shown in Figure 1. It is apparent that all the LOI values were increased with the increased loading of metal acetate, and then decreased at higher loading. The fire retardancy of PP with MnAc had the highest LOI values at $2 \mathrm{wt} \%$ loading and above.

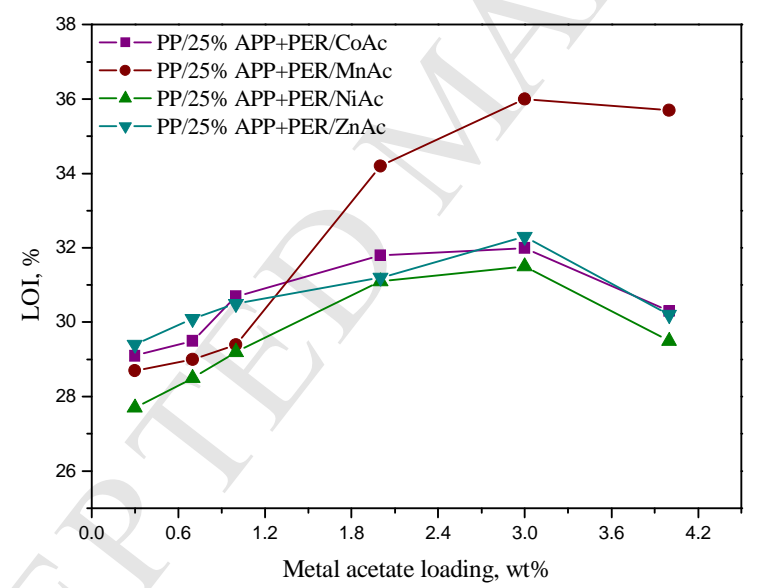

Figure 1 LOI values for fire retardant PP with 25 wt\% APP-PER mixture and different loading amounts of four metal acetates

\subsubsection{UL 94 tests}

Table 2 shows the results of the UL 94 tests of fire retarded PP with 25 wt\% APP-PER mixture and different metal acetate loadings. The UL-94 data agrees with that of LOI values, showing dependence on the amount of metal acetate. When the loading of metal acetates such as CoAc, NiAc and ZnAc increase from $0.3 \mathrm{wt} \%$ to $4 \mathrm{wt} \%$, the UL 94 rating was improved from $\mathrm{V}-2$ to $\mathrm{V}-0$ at first, and then decreased to $\mathrm{V}-2$ or 
lower. Although the V-0 ratings were only seen for all the PP/25APP+PER/MnAc systems in range of $0.7 \mathrm{wt} \%$ to $4 \mathrm{wt} \%$ of MnAc, only the samples with loadings 0.7 to $2.0 \mathrm{wt} \% \mathrm{MnAc}$ showed no flaming after the burner was removed. The sample at 3.0 wt\% MnAc showed burning after the burner was first removed, but not after the second application, while the sample at $4 \mathrm{wt} \%$ MnAc showed flaming after both applications of the burner. Thus a similar trend was observed for the samples containing MnAc to those flame retarded with CoAc, NiAc and ZnAc.

Table 2 UL-94 results for PP based composites

\begin{tabular}{|c|c|c|c|c|}
\hline \multirow{2}{*}{ Sample } & \multicolumn{2}{|c|}{$\mathbf{A F T}^{a}$} & \multirow{2}{*}{ Dripping } & \multirow{2}{*}{ UL-94 } \\
\hline & $t_{1}(s)$ & $\mathrm{t}_{2}(\mathrm{~s})$ & & \\
\hline $\mathrm{PP} / 25 \mathrm{APP}+\mathrm{PER}$ & 0.4 & 12.9 & Yes & $\mathrm{V}-2$ \\
\hline $\mathrm{PP} / 25 \mathrm{APP}+\mathrm{PER} / 0.3 \mathrm{CoAc}$ & 0.4 & 11.1 & Yes & $\mathrm{V}-2$ \\
\hline $\mathrm{PP} / 25 \mathrm{APP}+\mathrm{PER} / 0.7 \mathrm{CoAc}$ & 0.4 & 26.9 & Yes & $\mathrm{V}-2$ \\
\hline $\mathrm{PP} / 25 \mathrm{APP}+\mathrm{PER} / 1 \mathrm{CoAc}$ & 0 & 3.5 & No & $\mathrm{V}-0$ \\
\hline $\mathrm{PP} / 25 \mathrm{APP}+\mathrm{PER} / 2 \mathrm{CoAc}$ & 1.5 & 2.4 & No & $\mathrm{V}-0$ \\
\hline $\mathrm{PP} / 25 \mathrm{APP}+\mathrm{PER} / 3 \mathrm{CoAc}$ & 1.5 & 9.3 & Yes & $\mathrm{V}-2$ \\
\hline $\mathrm{PP} / 25 \mathrm{APP}+\mathrm{PER} / 4 \mathrm{CoAc}$ & 13.5 & 13.7 & Yes & $\mathrm{V}-2$ \\
\hline $\mathrm{PP} / 25 \mathrm{APP}+\mathrm{PER} / 0.3 \mathrm{MnAc}$ & 0.5 & 17.5 & Yes & $\mathrm{V}-2$ \\
\hline $\mathrm{PP} / 25 \mathrm{APP}+\mathrm{PER} / 0.7 \mathrm{MnAc}$ & 0 & 0 & No & $\mathrm{V}-0$ \\
\hline $\mathrm{PP} / 25 \mathrm{APP}+\mathrm{PER} / 1 \mathrm{MnAc}$ & 0 & 0 & No & $\mathrm{V}-0$ \\
\hline $\mathrm{PP} / 25 \mathrm{APP}+\mathrm{PER} / 2 \mathrm{MnAc}$ & 0 & 0 & No & $\mathrm{V}-0$ \\
\hline $\mathrm{PP} / 25 \mathrm{APP}+\mathrm{PER} / 3 \mathrm{MnAc}$ & 5.4 & 0 & No & $\mathrm{V}-0$ \\
\hline $\mathrm{PP} / 25 \mathrm{APP}+\mathrm{PER} / 4 \mathrm{MnAc}$ & 1.7 & 7.2 & No & $\mathrm{V}-0$ \\
\hline $\mathrm{PP} / 25 \mathrm{APP}+\mathrm{PER} / 0.3 \mathrm{NiAc}$ & 0 & 13.5 & Yes & $\mathrm{V}-2$ \\
\hline $\mathrm{PP} / 25 \mathrm{APP}+\mathrm{PER} / 0.7 \mathrm{NiAc}$ & 0.5 & 6.1 & Yes & $\mathrm{V}-2$ \\
\hline $\mathrm{PP} / 25 \mathrm{APP}+\mathrm{PER} / 1 \mathrm{NiAc}$ & 0 & 5.6 & No & $\mathrm{V}-0$ \\
\hline $\mathrm{PP} / 25 \mathrm{APP}+\mathrm{PER} / 2 \mathrm{NiAc}$ & 0.5 & 1.1 & No & $\mathrm{V}-0$ \\
\hline $\mathrm{PP} / 25 \mathrm{APP}+\mathrm{PER} / 3 \mathrm{NiAc}$ & 0.5 & 5.6 & No & $\mathrm{V}-0$ \\
\hline $\mathrm{PP} / 25 \mathrm{APP}+\mathrm{PER} / 4 \mathrm{NiAc}$ & 19.7 & Burns & Yes & No rating \\
\hline $\mathrm{PP} / 25 \mathrm{APP}+\mathrm{PER} / 0.3 \mathrm{ZnAc}$ & 0 & 4.6 & Yes & $\mathrm{V}-2$ \\
\hline $\mathrm{PP} / 25 \mathrm{APP}+\mathrm{PER} / 0.7 \mathrm{ZnAc}$ & 0 & 6.3 & Yes & $\mathrm{V}-2$ \\
\hline $\mathrm{PP} / 25 \mathrm{APP}+\mathrm{PER} / 1 \mathrm{ZnAc}$ & 0 & 2.9 & No & $\mathrm{V}-0$ \\
\hline $\mathrm{PP} / 25 \mathrm{APP}+\mathrm{PER} / 2 \mathrm{ZnAc}$ & 0.3 & 9.3 & No & $\mathrm{V}-0$ \\
\hline $\mathrm{PP} / 25 \mathrm{APP}+\mathrm{PER} / 3 \mathrm{ZnAc}$ & 0.4 & 14.9 & No & $\mathrm{V}-0$ \\
\hline $\mathrm{PP} / 25 \mathrm{APP}+\mathrm{PER} / 4 \mathrm{ZnAc}$ & Burns & Burns & Yes & No rating \\
\hline
\end{tabular}

$a$ : Average flaming time after the first and the second ignition 
The data in Table 2 shows there is an optimum loading for each metal acetate to improve the fire retardancy of PP/APP+PER. It also illustrates the dramatic effect of metal acetates on the dripping behaviour, and its relationship to flammability. Too much or too little metal acetate results in a decrease of LOI values and UL94 ratings. In order to study the mechanism and char-forming property of PP/APP+PER/metal acetate systems further, MnAc was selected from the four metal acetates for further studies (rheology and cone calorimetry) because of its better promotion of the fire retardancy of PP/APP+PER blends. Whatever, since the four metal acetates studied in this work had the similar trend in the data of LOI and UL94 tests, the mechanism for $\mathrm{PP} / \mathrm{APP}+\mathrm{PER} / \mathrm{MnAc}$ blends is also applicable for PP blends with other three metal acetates.

\subsection{Crosslink behaviour and dynamic combustion behaviour}

\subsubsection{Rheological analysis}

Rheology has been used to investigate the viscoelastic properties of thermoplastic polymers, to study crosslinking in fire retarded systems, and to better understand the structure-property relationships of polymer blends ${ }^{[19,20]}$. In order to clarify the interaction mechanism of MnAc, APP-PER mixture and PP, the viscosity of $\mathrm{PP} / 25 \mathrm{APP}+\mathrm{PER} / \mathrm{MnAc}$ blends were studied as a function of temperature under nitrogen. Since all oxygen is consumed at the flame front once a sample ignites, the tests in the atmosphere without oxygen are more suitable to study the behaviour of the fire retarded matrix during combustion ${ }^{[21]}$.

Figure 2 compares the flow behaviour of different PP/IFR systems to the neat PP. 
Clearly, the complex viscosity $\left(\eta^{*}\right)$ of the unfilled PP exhibits a monotonic and rapid decrease up to $350{ }^{\circ} \mathrm{C}$, while essentially zero values were measured above this temperature. Those trends are typical for a highly entangled polymer melt with positive flow activation energy ${ }^{[22]}$. In contrast, all PP/IFR composites exhibit pronounce deviation from this behaviour in the high temperature regime. The $\eta^{*}$ for the PP/IFR blend systematically drops upon heating within the range 230 to $340^{\circ} \mathrm{C}$, remains close to zero until $430{ }^{\circ} \mathrm{C}$, but then increases sharply. This behaviour holds true for all MnAc containing hybrids and points to the evolution of a chemically crosslinked network. During pyrolysis, the decomposition of APP leads to the release of ammonia and water, followed by the phosphorylation of PER. As dehydration and dephosphorylation proceed, crosslinked networks may form ${ }^{[5,8]}$. Evidently, metal acetates can play a catalytic role in this process, similar to the reports of hydroxyl and hydromethoxyl compounds in cellulose ${ }^{[23]}$. At $550{ }^{\circ} \mathrm{C}, \eta^{*}$ restores a value of 540 , 600, 670 and $800 \mathrm{~Pa}$ s for blends containing 1, 2, 3 and 4 wt\% MnAc, respectively.

Thus, MnAc promotes crosslinking, increasing the viscosity.

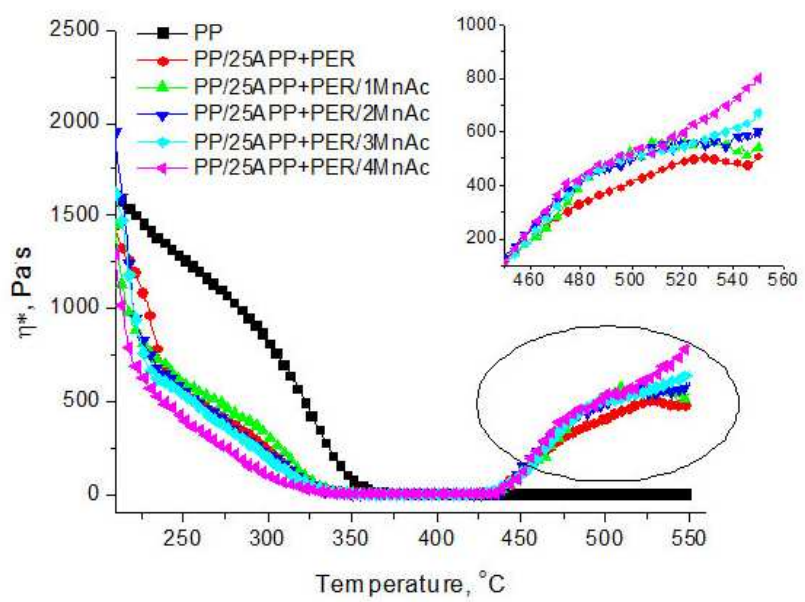

Figure 2 Plot for dependence of viscosity $\left(\eta^{*}\right)$ of the pure PP and PP/25APP+PER with different contents of MnAc on temperature, with inset showing a magnification of viscosity above $450{ }^{\circ} \mathrm{C}$. 


\subsubsection{Thermal gravimetric analysis}

In order to make clear that the metal acetates promote the reactions between APP and PER or they just promote the crosslinking of PP, we used TGA as the another method to study the crosslinking, since the change in the $T_{\max } \mathrm{S}$ or residual weights could help to analyze the crosslink behavior. So, the $T_{\max } \mathrm{s}$ and residual weights of pure PP, APP-PER mixture and their blends with MnAc were measured by TG analysis in $\mathrm{N}_{2}$ and air, respectively. The TG curves were shown in Figure 3 and Figure 4. The detailed data were listed in Table 3.

Seen from Figure $3\left(\mathrm{~N}_{2}\right)$, the TG curve of PP with 4 wt $\%$ MnAc (named as PP/4MnAc) was similar to that of pure PP. The experimental value of the residue at $700^{\circ} \mathrm{C}$ of $\mathrm{PP} / 4 \mathrm{MnAc}$ in $\mathrm{N}_{2}$ was less than the calculated one and the $T_{\max }$ of PP/4MnAc was similar to that of pure PP. These data indicated that the reaction between PP and MnAc did not occur in $\mathrm{N}_{2}$. However, it is interesting to find that such phenomena were changed when the atmosphere in TGA tests was air. As shown in Figure 3(Air), the max weight-loss curve of PP/4MnAc was shift obviously to higher temperature. The $T_{\max }$ of $\mathrm{PP} / 4 \mathrm{MnAc}$ in air increased to $389^{\circ} \mathrm{C}$ compared with that of PP/4MnAc in $\mathrm{N}_{2}$. This indicated that the addition of MnAc changed the degradation process of PP. $\mathrm{Mn}(\mathrm{II})$ is belonging to the multiple valency metal ions, which are known as oxidation catalyst $[8,24]$. In the thermal degradation in air, PP can be oxidized to form hydroperoxide [25]. After the addition of MnAc in PP, such oxidation of PP may be promoted by MnAc, and postpone the weight loss of PP to higher temperature. At the same time, more dehydration between hydroperoxides may form crosslinking between PP chains to some extent and more residue could be left, which was demonstrated in Table 3. The experimental value of the residue at $700^{\circ} \mathrm{C}$ of $\mathrm{PP} / 4 \mathrm{MnAc}$ in air was 2.9 $\mathrm{wt} \%$, which is slight higher than the calculated one. 

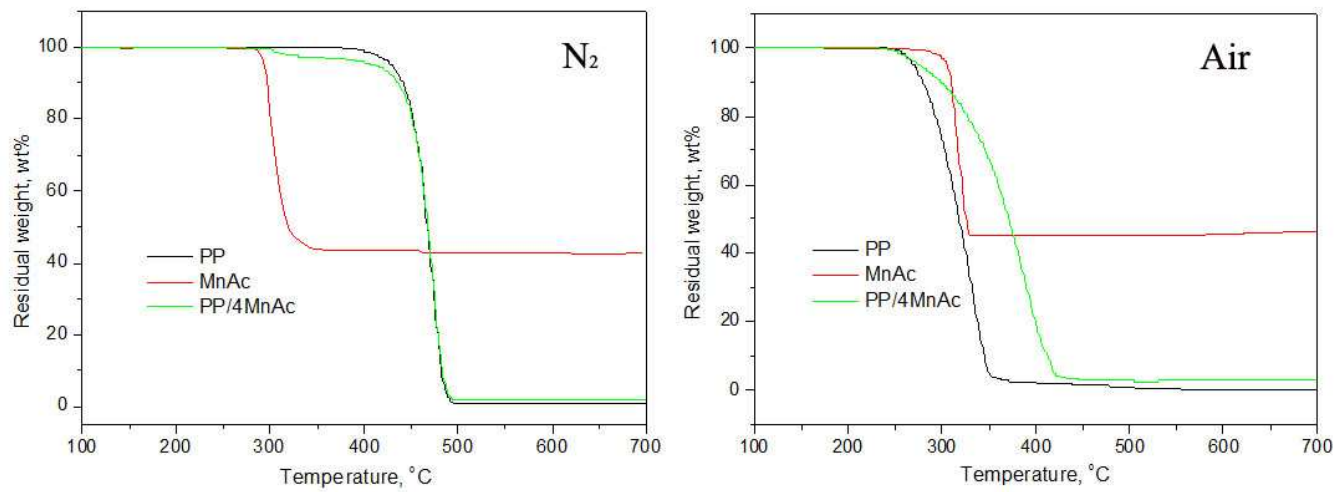

Figure 3 Comparison of TG curves of PP, MnAc and PP/4MnAc in $\mathrm{N}_{2}$ and air

As for the APP-PER mixture and MnAc system, the interaction between the APP-PER mixture and MnAc could be found in both $\mathrm{N}_{2}$ and air. Seen from Figure 4, the weight-loss slopes between $550-700^{\circ} \mathrm{C}$ in $\mathrm{N}_{2}$ and $600-700^{\circ} \mathrm{C}$ in air of $\mathrm{APP}+\mathrm{PER} / \mathrm{MnAc}$ were more gentle than those of APP+PER. The experimental values in $\mathrm{N}_{2}$ and air of the residue at $700^{\circ} \mathrm{C}$ of $\mathrm{APP}+\mathrm{PER} / \mathrm{MnAc}$ were $42 \mathrm{wt} \%$ and $38.1 \mathrm{wt} \%$, which is $11.5 \mathrm{wt} \%$ and $10.0 \mathrm{wt} \%$ higher than the calculated values, respectively. Prof. M. Lewin et $\mathrm{al}^{[8]}$ had reported the metal ions promote the crosslinking of APP. It may react with two monomeric phosphate groups and produce a bridge between two APP chains, which may enlarge the degree of polymerization of the APP and decrease the volatility of the phosphorus oxides during the pyrolysis ${ }^{[8]}$. More phosphorus may then favor the formation of char through the carbonization of PER.

According to the mentioned above, we concluded that the metal acetates promote both the crosslinking of APP-PER mixture and PP in air. While, when in the oxygen-free atmosphere, the promotion of MnAc for the crosslinking will happen in the APP-PER mixture but not in the PP. 

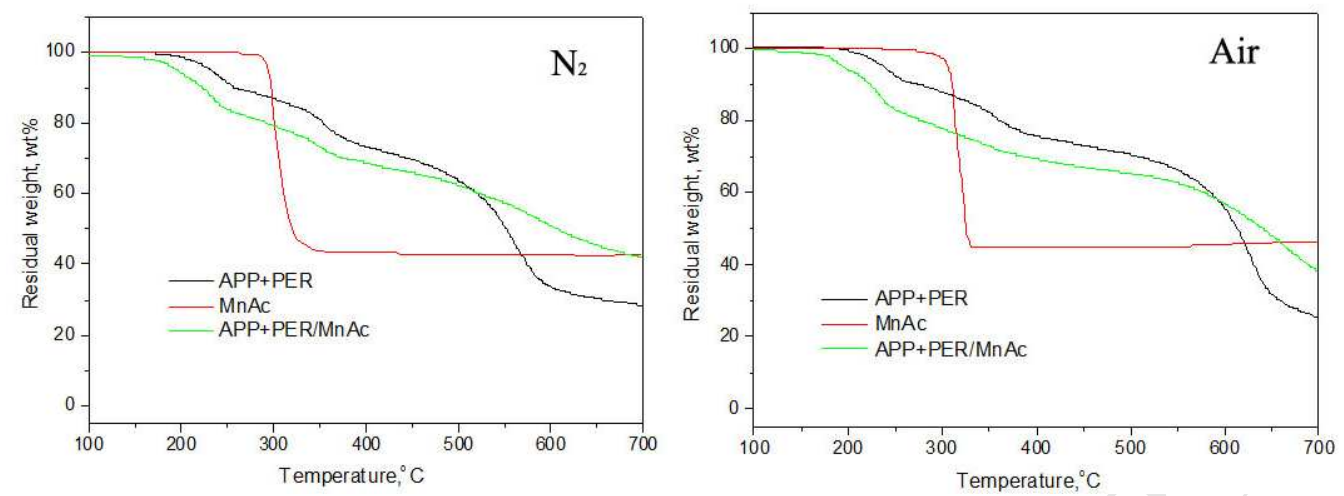

Figure 4 Comparison of TG curves of APP-PER mixture, MnAc and APP+PER/MnAc in $\mathrm{N}_{2}$ and air

Table 3 TG data of PP, APP-PER mixture, MnAc, PP/4MnAc and APP+PER/MnAc in $\mathrm{N}_{2}$ and air

\begin{tabular}{|c|c|c|c|c|c|c|}
\hline \multirow{3}{*}{ Sample } & \multirow{2}{*}{\multicolumn{2}{|c|}{$T_{\max } /{ }^{o} \mathrm{C}^{a}$}} & \multicolumn{4}{|c|}{ Residue at $700^{\circ} \mathrm{C} / \%$} \\
\hline & & & \multicolumn{2}{|c|}{ Exp. } & \multicolumn{2}{|c|}{ Cal. } \\
\hline & $\mathrm{N}_{2}$ & Air & $\mathrm{N}_{2}$ & Air & $N_{2}$ & Air \\
\hline $\mathrm{PP}$ & 471 & 331 & 0.8 & 0.2 & & \\
\hline APP+PER & $246,254,560$ & $241,354,626$ & 28.5 & 25.2 & & \\
\hline $\mathrm{MnAc}$ & 300 & 313,322 & 42.8 & 46.4 & & \\
\hline $\mathrm{PP} / 4 \mathrm{MnAc} c^{b}$ & 469 & 389 & 1.7 & 2.9 & 3.0 & 2.7 \\
\hline $\mathrm{APP}+\mathrm{PER} / \mathrm{MnAc} c^{c}$ & $231,348,584$ & $286,234,665$ & 42.0 & 38.1 & 30.5 & 28.1 \\
\hline
\end{tabular}

$a$ : maximum decomposition temperature, $b$ : the mass ratio of $\mathrm{PP}$ and MnAc is 71:4, $c$ : the mass ratio of APP+PER and MnAc is $25: 4$.

\subsubsection{Cone Calorimetry}

Cone calorimetry is used for investigating the dynamic combustion behaviour of polymeric materials, which can provide various parameters such as time to ignition $\left(t_{\text {ign }}\right)$, peak heat release rate (PHRR) and total heat release $\left(\right.$ THR) ${ }^{[26]}$. Table 4 and Figure 5 show the cone calorimeter data for PP, PP/25APP+PER and PP/25APP+PER/MnAc blends.

The data shown in Table 4 and Figure 5 indicate that PP burns very rapidly after ignition and a large PHRR of $1361 \mathrm{~kW} \cdot \mathrm{m}^{-2}$ appears at around $115 \mathrm{~s}$. The addition of APP-PER mixture in PP reduces the PHRR and THR values by $66.5 \%$ and $20.6 \%$, respectively, demonstrating APP-PER mixture slows down the combustion process. 
The promotional effect of MnAc with APP-PER mixture can be demonstrated, since all the PP/25APP+PER/MnAc blends had lower PHRR and THR values than that of the PP/25APP+PER blend. It is clear that PP/25APP+PER/2MnAc exhibit the lowest PHRR and THR values of $366 \mathrm{~kW} \cdot \mathrm{m}^{-2}$ and $74.1 \mathrm{MJ} \cdot \mathrm{m}^{-2}$, respectively. Greater or less loading of MnAc in PP/25APP+PER/MnAc blends results in an increase in the HRR and THR values, showing a similar trend to that in the LOI and UL 94 tests.

Table 4 Combustion parameters obtained from burning in the cone calorimeter test

\begin{tabular}{lcccc}
\hline \multicolumn{1}{c}{ Samples } & $t_{\text {ign }}$ & $\begin{array}{c}\text { PHRR } \\
/ \mathrm{kW} \cdot \mathrm{m}^{-2}\end{array}$ & $\begin{array}{c}\text { THR } \\
/ \mathrm{MJ} \cdot \mathrm{m}^{-2}\end{array}$ & $\begin{array}{c}\text { Residue } \\
/ \mathrm{wt} \%\end{array}$ \\
\hline PP & 24 & 1361 & 107.5 & 0 \\
PP/25APP+PER & 21 & 455 & 85.4 & 18.7 \\
PP/25APP+PER/1MnAc & 23 & 372 & 75.2 & 27.4 \\
PP/25APP+PER/2MnAc & 19 & 366 & 74.1 & 27.9 \\
PP/25APP+PER/3MnAc & 19 & 383 & 83.6 & 26.8 \\
PP/25APP+PER/4MnAc & 18 & 369 & 96.1 & 23.1 \\
\hline
\end{tabular}
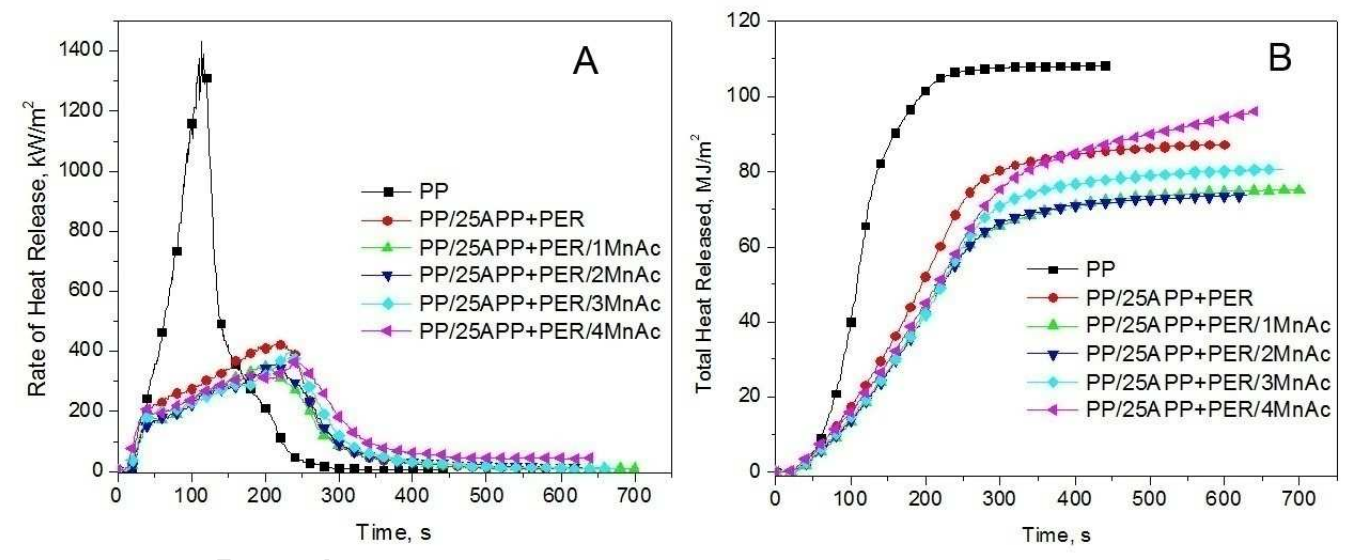

Figure 5 (A) Heat release rate curves and (B) total heat release curves of PP with 25 wt \% APP-PER mixture and different loadings of MnAc in the cone calorimeter test

\subsection{Mechanistic Investigation}

Rheological data at high temperatures, indicate that the crosslink density systematically increases with increasing metal acetate content. Since the higher viscosity of the blends in the molten state will reduce the volatilization of degradation 
products during the burning process, the higher melt viscosity will contribute to the improved fire retardancy of the blends ${ }^{[27]}$.

However, the crosslinking also affect the charring process, which is very important to the formation of the protective transition char layer during combustion. It has largely been neglected in the literature but might find answers from the coal chemistry ${ }^{[28]}$. A crucial coal characteristic is its caking property that describes the plasticity and is the key to the quality of the protective char ${ }^{[29]}$.

Obviously, too much crosslinking in the molten polymer will presumably prevent the free flowing and joining of the transition char during combustion, then provided bypasses for the heat and mass transfer and thus inflammable gaseous products eventually evolved in flame retarded PP burnt samples. Du ${ }^{[20]}$ also found that too much crosslinking caused large crevasses and cracks in the char which consequently led to severe deterioration of flame retardancy. Therefore, there is an optimum loading range of MnAc in the fire retarded $\mathrm{PP}$, which is a balance between formation of a network structure and quality of the carbonaceous char during combustion. That is the reason for explaining the trend in the LOI, UL94 and cone calorimetric data of fire retarded PP containing MnAc.

The mechanism for the burning behaviour is also demonstrated by the nature of the final residue char. Photographs of the char after cone calorimetry are shown in Figure 6. Figure 6(A) shows a large broken crevasse in the middle of the residue of the $\mathrm{PP} / 25 \mathrm{APP}+\mathrm{PER}$ sample, demonstrating that the char layer is fragile and easily broken during burning without the catalysis of MnAc. The PP/25APP+PER/1MnAc residue 
shown in Figure 6(B) shows a smaller crevasse than in Figure 6(A). This is because the MnAc increased the viscosity and improved crosslinking. As well as hindering the volatilization of degradation products, the improved crosslinking strengthened the char layer and increased the yield of residue, decreasing PHRR and THR. Table 4 shows the weight of $\mathrm{PP} / 25 \mathrm{APP}+\mathrm{PER} / 1 \mathrm{MnAc}$ residue increased to $27.4 \mathrm{wt} \%$ as expected, $8.7 \%$ higher than that of PP/25APP+PER. When the loading of the MnAc was increased to $2 \mathrm{wt} \%$, an even more coherent and fully intumesced layer formed, shown in Figure 6(C). This material gave the greatest yield of the residue. Although the PP/25APP+PER/3MnAc and PP/25APP+PER/4MnAc samples shown in Figure 6 (D) and (E), show less cracks or fissures on the char residues, the higher THR values of 83.6 and $96.1 \mathrm{MJ} \cdot \mathrm{m}^{-2}$ demonstrated that the plasticity and fluidity of the transition char during combustion was weakened by higher crosslink degree by the more loading of MnAc, which resulted in worse flame retardancy with increased THR, allowing more flammable degradation products to be released. 

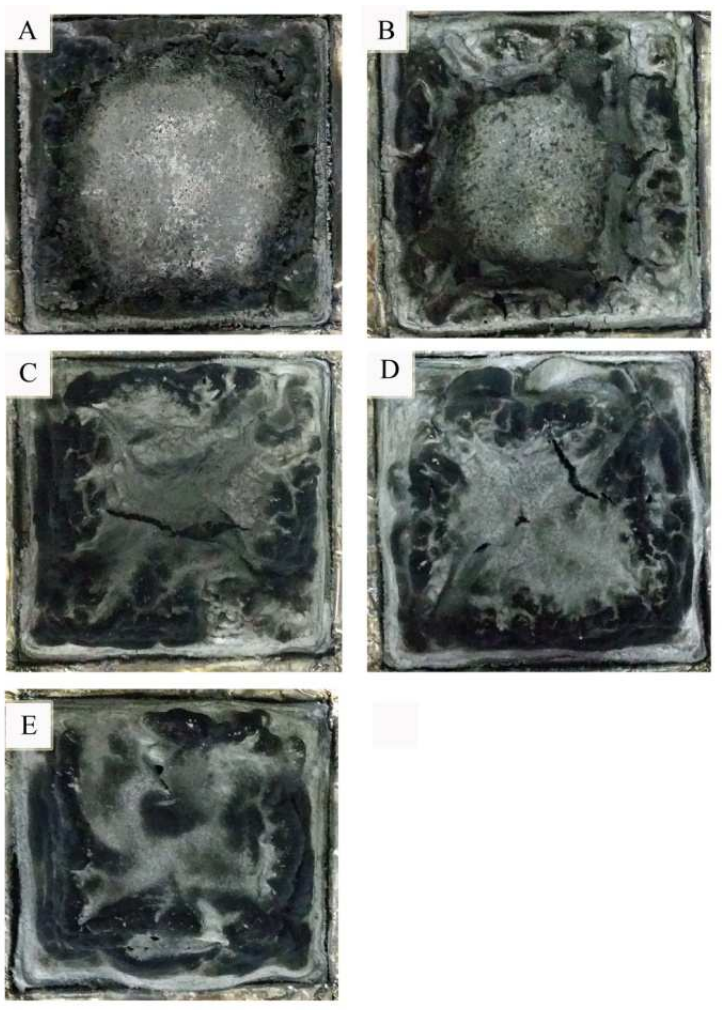

Figure 6 Optical images of residues after the cone calorimeter test for (A) PP/APP+PER, (B) $\mathrm{PP} / \mathrm{APP}+\mathrm{PER} / 1 \mathrm{MnAc},(\mathrm{C}) \mathrm{PP} / \mathrm{APP}+\mathrm{PER} / 2 \mathrm{MnAc}$, (D) PP/APP+PER/3MnAc, (E) $\mathrm{PP} / \mathrm{APP}+\mathrm{PER} / 4 \mathrm{MnAc}$

Moreover, Table 4 shows that the $t_{\text {ign }}$ of most PP/25APP+PER/MnAc materials were shortened with the increase loading of MnAc. Unlike PP can melt and be cooled by liquid phase convection, the loading of MnAc in the intumescent flame retarded PP increases the viscosity of the matrix reducing heat transfer between the exposed sample surface and the bulk of the sample, then results the surface getting hotter more quickly ${ }^{[17,30]}$. The surface of the samples with more MnAc may easily reach the critical surface temperature for ignition more quickly than the sample with less MnAc, thus probably causes the increase in the $t_{\text {ign }}$.

The description above presented the reason for the data trend of flame retarded PP affected by MnAc. Since they have the similar trend in LOI and UL94 results, it is 
reasonable to assume that the above mechanism is similarly valid for CoAc, NiAc and ZnAc.

\section{Conclusions}

The incorporation of small quantities of metal acetates into the PP/25APP+PER system has a significant influence on the fire behaviour of PP formulations. The rheological data of $\mathrm{PP} / 25 \mathrm{APP}+\mathrm{PER} / \mathrm{MnAc}$ blends indicates that the viscosity increase is dependent on the MnAc loading, where it promotes crosslinking. TGA data showed that MnAc promoted both the crosslinking of APP-PER mixture and PP in air while the promotion of MnAc for the crosslinking will happen in the APP-PER mixture but not in the PP when in the oxygen-free atmosphere. From the analysis of the data of LOI, UL94 and cone calorimetry, there is a balance between formation of a network structure and quality of the carbonaceous char during combustion. Too much crosslinking may decrease plasticity and fluidity of the transition char during combustion resulting in the worse flame retardancy. Only the optimum loading of MnAc can improve the fire retardancy of the intumescent flame retardant PP. The above conclusion is also valid for other metal acetates such as CoAc, NiAc and ZnAc studied in this work.

\section{ACKNOWLEDGMENTS}

The authors are grateful for the support of the National Natural Science Foundation of China (No.51203136), Ningbo Natural Science Foundation of China (No. 2016A610209) and the Ningbo Science and Technology Innovation Team (No. 2015B11005). 


\section{Reference:}

[1] Bourbigot S, Le Bras M, Duquesne S, Rochery M. Recent advances for intumescent polymers. Mater Chem Phys 2004; 289(6):499-511.

[2] Nie SB, Hu Y, Song L, He SQ, Yang DD, Study on a novel and efficient flame retardant synergist-nanoporous nickel phosphates VSB-1 with intumescent flame retardants in polypropylene. Polym Adv Technol 2008; 19(6):489-495.

[3] Halpern Y, Mott DM, Niswander RH, Fire retardancy of thermoplastic materials by intumescence. Ind Eng Chem Prod Res Dev 1984; 23(2):233-238.

[4] Meng XY, Ye L, Zhang XG, Tang PM, Tang JH, Ji X, Li ZM, Effects of expandable graphite and ammonium polyphosphate on the flame-retardant and mechanical properties of rigid polyurethane foams. J Appl Polym Sci 2009; 114(2):853-863

[5] Lewin M, Synergism and catalysis in flame retardancy of polymers. Polym Adv Technol 2001; 12(3-4):215-222.

[6] Braun U, Bahr H, Sturm H, Schartel B. Flame retardancy mechanisms of metal phosphinates and metal phosphinates in combination with melamine cyanurate in glass-fiber reinforced poly(1,4-butylene terephthalate): the influence of metal cation. Polym Adv Technol 2008; 19(6):680-692.

[7] Kashiwagi T, Danyus R, Liu M, Zammarano M, Shields JR. Enhancement of char formation of polymer nanocomposites using a catalyst. Polym Degrad Stabil 2009; 94(11):2028-2035.

[8] Lewin M, Endo M, Catalysis of intumescent flame retardancy of polypropylene by metallic compounds. Polym Adv Technol 2003; 14(1):3-11.

[9] Wu N, Yang RJ, Effects of metal oxides on intumescent flame-retardant polypropylene. Polym Adv Technol 2011; 22(5):495-501.

[10] Cai YB, Hu Y, Song L, Xuan SY, Zhang Y, Chen ZY, Fan WC, Catalyzing carbonization function of ferric chloride based on acrylonitrileebutadieneestyrene copolymer/organophilic montmorillonite nanocomposites. Polym Degrad Stabil 2007; 92(3):490-496.

[11] Hassan MA, Shehata AB, The effect of some polymeric metal chelates on the flammability properties of polypropylene. Polym Degrad Stabil 2004; 85(1):733-740.

[12] Song PA, Fang ZP, Tong LF, Jin YM, Lu FZ, Effects of metal chelates on a novel oligomeric intumescent flame retardant system for polypropylene. J Anal Appl Pyrolysis. 2008; 82(2):286-291.

[13] Cao ZH, Zhang Y, Song PA, Cai YZ, Guo Q, Fang ZP, Peng M, A novel zinc chelate complex containing both phosphorus and nitrogen for improving the flame retardancy of low density polyethylene. J Anal Appl Pyrolysis 2011; 92(2):339-346.

[14] Zhang Y, Li XN, Cao ZH, Fang ZP, Hull TR, Stec AA, Synthesis of Zinc Phosphonated Poly(ethylene imine) and Its Fire-Retardant Effect in Low Density Polyethylene. Ind Eng Chem Res 2015; 54(13):3247-3256

[15] Zhang P, Song L, Lu HD, Hu Y, Xing WY, Ni JX, Wang J, Synergistic effect of nanoflaky manganese phosphate on thermal degradation and flame retardant properties of intumescent flame retardant polypropylene system. Polym Degrad 
Stabil 2009; 94(2):201-207.

[16] Price D, Liu Y, Hull TR, Milnes GJ, Kandola BK, Horrocks AR. Flame retardance of poly(methyl methacrylate) modified with phosphorus-containing compounds. Polym Degrad Stabil 2002; 77(2):227-233.

[17] Wang DY, Liu Y, Wang YZ, Artiles PC, Hull TR, Price D, Fire retardancy of a reactively extruded intumescent flame retardant polyethylene system enhanced by metal chelates. Polym Degrad Stabil 2007, 92(8):1592-1598.

[18] Demir H, Arkış E, Balköse D, ÜlküS, Synergistic effect of natural zeolites on flame retardant additives. Polym Degrad Stabil 2005, 89(3):478-483.

[19] Qian Y, Wei P, Jiang PK, Zhao XM, Yu HZ. Synthesis of a novel hybrid synergistic flame retardant and its application in PP/IFR. Polym Degrad Stabil 2011; 96(6):1134-1140.

[20] Du BX, Fang ZP. Effects of carbon nanotubes on the thermal stability and flame retardancy of intumescent flame-retarded polypropylene. Polym Degrad Stabil 2011; 96(10):1725-1731.

[21] Zhang Y, Chen XL, Fang ZP, Synergistic effects of expandable graphite and ammonium polyphosphate with a new carbon source derived from biomass in flame retardant ABS. J Appl Polym Sci 2013; 128(4): 2424-2432.

[22] Kelarakis A, Krysmann MJ, Giannelis EP. Thermoreversible gelation in poly(ethylene oxide)/carbon black hybrid melts. Polymer 2014; 55(24):6278-6281.

[23] H. A. Petersen, In Chemical Processing of Fibers and Fabrics, Vol. II, Functional Finishes, Part A, Lewin M, Sello SB(eds). Dekker: New York, 1984; 48-318

[24] Day M, Cooney JD, MacKinnon M. Degradation of contaminated plastics: a kinetic study. Polym Degrad Stabil 1995; 48(3): 341-349

[25] Gugumus F. Re-examination of the thermal oxidation reactions of polymers 3. Various reactions in polyethylene and polypropylene. Polym Degrad Stabil 2002; 77(1): $147-155$.

[26] Schartel B, Hull TR, Development of fire-retarded materials-Interpretation of cone calorimeter data. Fire Mater 2007, 31(5):327-354.

[27] Song PA, Liu H, Shen Y, B. X. Du, Z. P. Fang, Y. Wu. Fabrication of dendrimer-like fullerene (C60)-decorated oligomeric intumescent flame retardant for reducing the thermal oxidation and flammability of polypropylene nanocomposites. $\mathrm{J}$ Mater Chem, 2009, 19(9):1305-1313.

[28] Huang K, Yao Q. Rigid and steric hindering bisphosphate flame retardants for polycarbonate. Polym Degrad Stabil 2015; 113:86-94.

[29] Kidnena K, Murata S, Nomura M. Investigation on coal plasticity: correlation of the plasticity and a TGA-derived parameter. Energ Fuel 1998; 12(4):782-787.

[30] Nyambo C, Kandare E, Wang DY, Wilkie CA, Flame-retarded polystyrene: Investigating chemical interactions between ammonium polyphosphate and $\mathrm{MgAl}$ layered double hydroxide. Polym Degrad Stabil 2008, 93(9), 1656-1663. 